\title{
The initiation and linkage of surface fractures above a buried strike-slip fault: An experimental approach
}

\author{
N Ghosh and A Chattopadhyay \\ Department of Geology, Delhi University, Delhi 110 007, India.
}

\begin{abstract}
Surface fractures in the overburdened sedimentary rocks, formed above a deep-seated basement fault, often provide important information about the kinematics of the underlying master fault. It has already been established that these surface fractures dynamically evolve and link one another with progressive displacement on the master fault below. In the present study, two different series of riedel-type experiments were carried out with clay analogue models under different boundary conditions viz., (i) heterogeneous simple shear of the cover rocks above a buried strike slip fault (wrench system) and (ii) heterogeneous simple shear with a component of shear-normal compression of the overburden package above a basement fault (transpressional system), to observe the initiation and linkage of surface fractures with varying $T^{\prime}$ (where $T^{\prime}=$ thickness of the overburden normalized with respect to the width of the master fault). In the wrench system, Riedel (R) shears were linked by principal displacement (Y) shears at early stages (shear strain of 0.8 to 1 ) in thin $\left(2<T^{\prime}<18\right.$ ) models and finally (at a minimum shear strain of 1.4) gave rise to a through-going fault parallel to the basement fault without development of any other fracture. Conjugate Riedel $\left(\mathrm{R}^{\prime}\right)$ shears develop only within the thicker $\left(T^{\prime}>18\right)$ clay models at a minimum shear strain of 0.7 . With increasing deformation (at a minimum shear strain of 1.2) two $\mathrm{R}^{\prime}$ shears were joined by an $\mathrm{R}$ shear and finally opened up to make a sigmoidal vein with an asymmetry antithetic to the major faultmovement sense. Under transpression, the results were similar to that of heterogeneous simple shear for layers $2<T^{\prime}<15$. In layers of intermediate thickness $\left(15<T^{\prime}<25\right)$ early formed high angle $\mathrm{R}$ shears were cross cut by low angle $\mathrm{R}$ shears (at a minimum shear strain of 0.5 and shortening of $0.028)$ and "Riedel-within-Riedel" shears were formed within thick $\left(T^{\prime}>25\right)$ models (at minimum shear strain of 0.7 and shortening of 0.1 ), with marked angularity of secondary fault zone with the master fault at depth.
\end{abstract}

\section{Introduction}

In many natural examples it has been observed that secondary fractures were formed within the sediment cover above large, seismically active strike-slip faults within the basement, e.g., Dashte-Bayaz fault zone in Iran (Tchalenko and Ambraseys 1970). Secondary fracturing spatially associated with a slipping fault is referred to as damage. Damage zones around faults occur because of stress concentration or to accommodate displacement variations along faults (Segall and Pollard 1980; Kim et al 2003). Detailed study of the surface fractures within the damage zone helps to understand the kinematics of the basement fault. The major types of fractures, which may not occur all together in the damage zone at a time, are Riedel shears $(\mathrm{R})$, conjugate Riedel shears $\left(\mathrm{R}^{\prime}\right), \mathrm{P}$ shears, $\mathrm{Y}$ shears and tension $(\mathrm{T})$ fractures (Swanson 1988). The idealised orientation of those fractures for simple shear and transpression are shown in figure 1(a) and 1(b) respectively. In simple shear, $\mathrm{R}^{\prime}$ and $\mathrm{R}$ shears will initiate at an angle of $45^{\circ} \pm \phi / 2$ with the shear plane and $\mathrm{P}$ shears at an angle of $\left(-45^{\circ}+\phi / 2\right)$. Tension fractures will initiate at an angle of $45^{\circ}$ with the shear

Keywords. Heterogeneous simple shear; transpression; Riedel shears; Sigmoidal veins; strike-slip fault. 


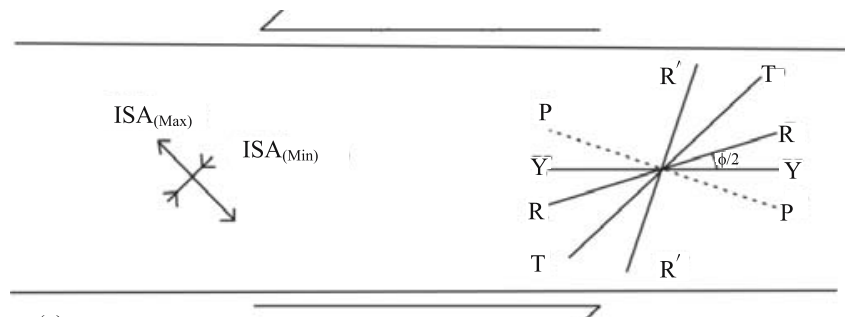

(a)



(b)

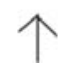

Figure 1. Schematic representation of idealized geometry of Riedel shears $(\mathrm{R})$, conjugate Riedel shears $\left(\mathrm{R}^{\prime}\right), \mathrm{P}$ shears and tension fractures $(T)$. (a) For simple shear and (b) for transpression (after Sanderson and Marchini 1984). ISA $=$ Instantaneous stretching axis.

plane (where $\phi$ is the angle of internal friction). For transpressional deformation, the fractures will be at a relatively higher angle with the shear plane compared to the conventional orientation in simple shear depending on the ratio of pure shear and simple shear. However, along with internal angle of friction, the actual orientation of the fractures are also controlled by strain rate, stress state (Ahlgren 2001) and vorticity (Smith and Durney 1992).

Riedel (1929) first experimentally produced these shear fractures in clay models under simple shear and also reported that the length of individual shears and width of the shear zone depends on the thickness of the overlying clay layer. Since then extensive experimental work has been done on the formation of shear fractures under different boundary conditions but only Naylor et al (1986) and Atmaoui et al (2006) have studied the effect of thickness of the overburden on the surface fracture pattern. Tchalenko (1970) examined the extent of structural similarity between shear zones of different magnitudes, e.g., on microscopic scale (shear box test), on intermediate scale (Riedel shear experiment), and on regional scale (earthquake fault). In shear zones of all scales first $\mathrm{R}$ and $\mathrm{R}^{\prime}$ shears were formed at peak stage, $\mathrm{P}$ shears were formed at post peak stage and $\mathrm{Y}$ shears were formed at residual stage. In the experiments of Wilcox et al (1973), folds formed early and were accompanied or followed by conjugate strike-slip faults, reverse or normal faulting developed under parallel wrenching, basins formed under divergent wrenching and upthrust blocks formed in convergent wrenching. Bartlett et al (1981) experimentally induced strike-slip fault zones in intact layers of Indiana limestone. In their experiments $\mathrm{R}$ and $\mathrm{P}$ shears formed concurrently in peak shear strength. In post-peak shear strength R, P X (shear fracture at an angle $-(45+\phi / 2)$ with the shear plane $)$ and $\mathrm{R}^{\prime}$ shears together formed a through-going interconnected network. They also reported that the shear zone widens upwards from the sharp master fault. In and beyond pre-residual shear strength $\mathrm{Y}$ shears were formed along which most of the displacement was accomplished. The formation of shear fracture pattern under direct shear was studied by Gammond (1983). Naylor et al (1986) have studied the variation in fracture pattern with varying sandpack thickness under basement controlled pure wrenching, transpression and transtension. Their experiments show that the $\mathrm{R}$ shear lengths can be used to determine the approximate thickness of sediment overlying the basement fault. The $\mathrm{R}$ shears have a helicoidal shape in 3-dimension which states that the angle of $\mathrm{R}$ shears with the basement fault increases with increasing thickness of the overburden. Atmaoui et al (2006) also studied the influence of the thickness of clay slab on the fracture pattern. In their experiments $\mathrm{R}^{\prime}$ shears appear only after a critical thickness. The width of the shear zone as well as the tendency of overlap of $\mathrm{R}$ shears was increased with increasing thickness. Apart from these, the evolution of shear fracture patterns were studied under boundary conditions varying from pure wrench to pure divergence by Smith and Durney (1992), under distributed simple shear by Schreurs (1994), under distributed transpression and transtension by Schreurs and Colleta (1998), under pure shear by Marques (2001), under pure wrenching by Atmaoui et al (2006), and under homogeneous simple shear by Coelho et al (2006).

Detailed field studies have been very useful for understanding the evolution of secondary fractures related to faulting. Important contributions include:

(i) mapping of Riedel shear zones in Jurassic Navajo sandstone (Davis et al 1999),

(ii) field mapping and three dimensional modeling to study the progressive temporal evolution of Riedel shear zones (Ahlgren 2001),

(iii) study of fracture types in the damage zones from Gozo Island, Malta (Kim et al 2003),

(iv) study of outcrop-scale riedel structure network in relation to the progressive accumulation and localization of shear strain from Capitol Reef National Park, Utah (Katz et al 2004). 
Rigorous theoretical models, e.g., two-dimensional model of a discontinuous fault composed of interacting segments (Segall and Pollard 1980), initiation and formation of dilatant en echelon cracks by Pollard et al (1982) provide important insight into the mechanics of initiation and linkage of fault related secondary fractures.

The present series of experiments study the initiation, linkage and opening up of shear fractures in clay analogue models under heterogeneous simple shear and heterogeneous transpression. A special emphasis is made on the variation in fracture linkage with varying thickness of the deforming clay layer. The general aim of this study was to investigate the spatial and temporal variations in the surface fracture patterns above a buried, active strike slip fault, and to figure out a predictive relationship, if any, between the surface fracture patterns and the depth, and kinematics, of the underlying master fault.

\section{Experimental method}

\subsection{Modeling technique}

A combined simple shear and pure shear apparatus (figure 2) was designed to deform both brittle and ductile material at a very slow rate $(2 \mathrm{~mm} / \mathrm{min})$. The idea of this machine was taken from some earlier cited experimental works (Withjack and Jamison 1986; Tikoff and Peterson 1998). A pair of wooden blocks attached to a pair of converging pistons deformed the model kept between them. The angle of convergence $(\alpha)$ (effected by the angularity of the pushing blocks) would determine the

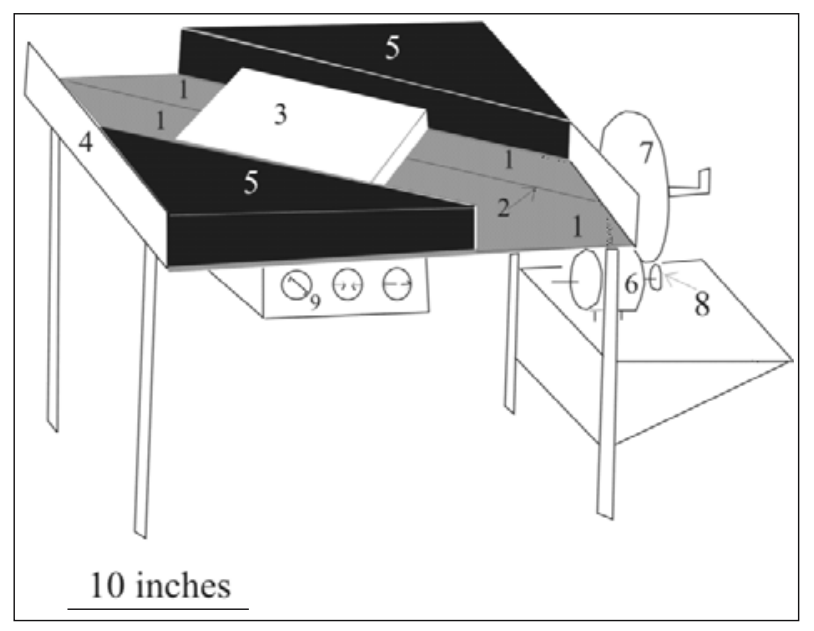

Figure 2. Schematic diagram of a combined simple shear and pure shear apparatus. (1) Two basement plates, (2) junction of the base plates, (3) soft model, (4) movable pistons, (5) angular wooden blocks, (6) reversible motor,

(7) gear of large diameter, (8) gear of smaller diameter and

(9) electrical switch board. ratio of pure shear and simple shear acting on the model, in a general transpressive system. To simulate a basement fault, a pair of thin base plates (wooden), capable of sliding past each other, was used. The edges of the plates were matched exactly with one another and the width of the junction (and therefore that of the master fault zone) was $1 \mathrm{~mm}$. The basal plates and the wooden blocks could move simultaneously under compression by the piston (figure 3). However the basal plates could also slip sidewise under the wooden pushing blocks, so that the pushing blocks could converge, if necessary, without distorting the sliding basal plates (figure $3 \mathrm{~b}$ ). This type of modeling technique generally conforms to the 'riedel-type' experiments (Tchalenko 1970) and essentially creates basement-induced heterogeneous simple shear in the soft models resting above the sliding master fault.

Two types of boundary conditions were used for the experiments:

(i) Wrench set up - where the soft clay model was deformed by two parallel, sliding pushing blocks $(\alpha=0)$ and the sliding basal fault (figure $3 \mathrm{a}$ ), which created a high-strain shear zone directly above the basement fault. Complete adherence between the model and the sliding basal plates was ensured by sticking sand paper (with grain size much coarser than the clay used for analogue modeling) on the base plates on which the model was kept.

(ii) Wrench-dominated transpressional set up where angular pushing blocks with low angle of convergence $(\alpha \sim 15$ and $\sim 30$ degrees) were used to deform the models (figure 3b). No sandpaper was used and model was allowed to slip over the base plate. Some degree of viscous coupling between the model and the moving basal plates was, however, achieved because of the soft, sticky nature of the clay.

In both cases, models were rested on the base plates and adjusted to fit well within the spacing between the angular blocks. The basal faults were always kept parallel with the pushing blocks, and slipping in the same sense. In nature, these set ups roughly simulate a major strike slip basement fault system with a package of sedimentary rocks deforming by basement-induced wrenching and/or transpression.

Models were made up of clay mixed with water in the ratio 3:1. Approximate undrained shear strength of the clay paste was around $2 \mathrm{KPa}$ (after Atmaoui et al 2006). Clay layers of varying thickness were used to test the variation in surface fracture geometry with the master fault at different depths. For describing the results, a dimensionless 


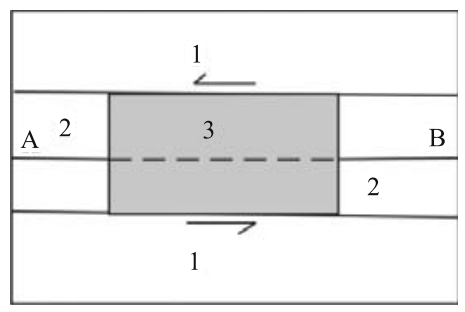

(a)



(b)

Figure 3. Schematic representation of the top view of the experimental set-up: (a) heterogeneous simple shear and (b) heterogeneous transpression; (1) wooden pushing blocks, (2) two thin wooden base plates simulating the basement fault capable of sliding past each other along AB, (3) clay model, (4) $\alpha=$ angle of convergence (in b) and (5) AB - basement fault and trace of basement fault in all subsequent figures.

parameter $T^{\prime}$ (ratio of thickness of the clay model to the width of the underlying master fault zone) was used, rather than using the absolute values of model thickness. On the upper surface of the clay layer, parallel straight-line markers, normal to the shear/slip direction, were drawn to measure the displacement and corresponding shear strain at each step. The models were always deformed by sinistral sense of shear. The angles made by the fractures with the basement fault were measured positive in an anticlockwise direction. Photographs were taken at each step of deformation by a digital camera and transferred to the computer for further analysis.

\subsection{Limitations of the modeling}

The clay models were not strictly scaled to the shear strength and cohesion of the sedimentary rocks they are supposed to simulate (Naylor et al 1986). However, clay models have been widely used to simulate rupture patterns in upper crustal rocks (Tchalenko 1970; Wilcox et al 1973; Smith and Durney 1992; Marques 2001). Despite their rather ductile behaviour prior to fracturing, the results are remarkably similar to natural structures. Clay models have an added advantage of easy handling, and because of their cohesion, fracture walls do not easily collapse unlike those in dry sand, and therefore can show the changing shape of the fractures with progressive strain, as described later. In nature, these opening fractures can actually be rapidly filled with material precipitated from circulating fluids.

The experimental set-up for transpression was not exactly similar to that of a natural transpressive fault. The base plates could only slide past each other and could not converge to give rise to a transpressive basement fault. However, it could roughly simulate the effect of basementinduced shearing and shear-normal compression in the cover rocks which is expected to occur in a natural transpressional zone. It was observed in our experiments that with increasing thickness of the cover the effect of basement fault-slip over the surface fracture pattern become less and the wall parallel and/or wall normal components of deformation become dominant. The results of the experiments with thicker overburden should therefore be at least qualitatively applicable to nature. But for thinner layers, where the effect of basement was dominant, the results may vary from a true transpressive system.

We did not use circular impression markers for measurement of finite strain as those could interfere with the initiation of the riedel shear fractures. For simple shear deformation the bulk shear strain could be measured from the displacement of line markers vis-à-vis the width of the shear zone, but for transpression we could not measure the finite strain. In this case we have measured shear strain (from displacement/width) and the layer normal shortening separately, to give a rough idea of increasing deformation intensity.

\section{Experimental results}

\subsection{Heterogeneous simple shear (basement-induced wrench system)}

\section{1a Models with $2 \leq T^{\prime} \leq 18$}

The first noticeable effect of deformation was observed (at shear strain $(\gamma)=0.8$ to 1 ) by the formation of $\mathrm{R}$ shears (figure 4). The angle of initiation of $\mathrm{R}$ shear was increased with increasing thickness of the model. For example, as shown in figure 5, for models with $T^{\prime}=2$ most of the $\mathrm{R}$ shears were initiated at angles between $5^{\circ}$ and $10^{\circ}$, few initiated between $10^{\circ}$ and $15^{\circ}$ and few between $15^{\circ}$ and $20^{\circ}$. For models with $T^{\prime}=8$ maximum $\mathrm{R}$ shears were initiated at angles between $15^{\circ}$ and $20^{\circ}$ but very few initiated between $5^{\circ}$ and $10^{\circ}$, $10^{\circ}$ and $15^{\circ}$ and $20^{\circ}$ and $25^{\circ}$. But for models with $T^{\prime}=18$ maximum $\mathrm{R}$ shears were initiated between 




Figure 4. $\mathrm{R}$ shears with a lower initial angle.

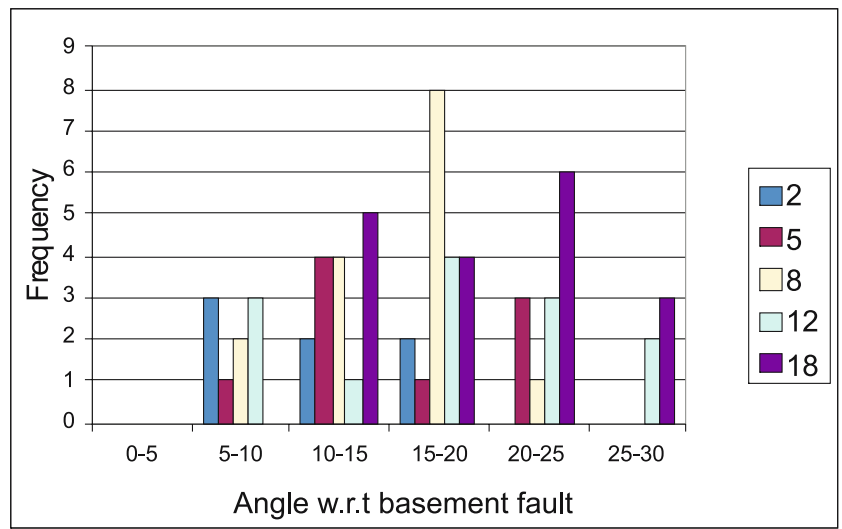

Figure 5. Frequency distribution plot of variation in initial angle of $\mathrm{R}$ shear w.r.t basement fault under heterogeneous simple shear for layers up to $2 \leq T^{\prime} \leq 18$.



Figure 6. Joining of $\mathrm{R}$ and $\mathrm{Y}$ shears gave rise to sigmoidal fractures. $R R-R$ shear, $Y Y-Y$ shear.

$20^{\circ}$ and $25^{\circ}$, some initiated between $10^{\circ}$ and $15^{\circ}$, $15^{\circ}$ and $20^{\circ}$ and $25^{\circ}$ and $30^{\circ}$. But notably in those layers not a single fracture was initiated between $5^{\circ}$ and $10^{\circ}$.

Within thinner models $\left(T^{\prime} \sim 2-8\right)$, with increasing deformation (at a minimum $\gamma=1.3$ ) small $\mathrm{Y}$ shears originate from the tips of $\mathrm{R}$ shears - giving rise to sigmoidal fractures (figure 6). Gradually those Y-shears extend parallel to the basement fault and merge with each other to make a throughgoing fault (at a minimum $\gamma=1.4$ ).

In some models $\left(T^{\prime} \sim 8-18\right)$, a set of high angle $\mathrm{R}$ shears $\left(28^{\circ}-34^{\circ}\right)$ cross cut the early formed low angle $\mathrm{R}$ shears with increasing deformation (at a minimum $\gamma=1.1$ ) (figure 7), similar to the high angle synthetic splay faults observed in sand models by Naylor et al (1986). Finally (at a minimum

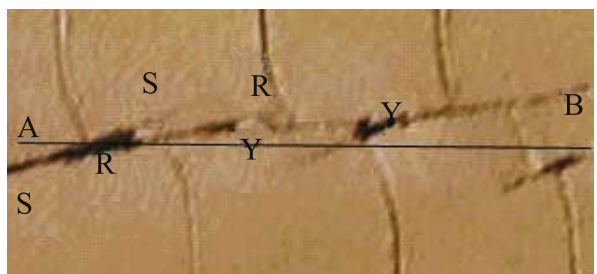

Figure 7. High angle R shears (SS) similar to synthetic splay faults as described by Naylor et al (1986), cross-cutting the low angle R shears (RR). YY - Y shears originating from the tip of the low angle $R$ shears $(R R)$.



Figure $8 . \quad R^{\prime}$ shears rotated to a sigmoidal shape and offset as passive markers due to slip along $R$ shears.

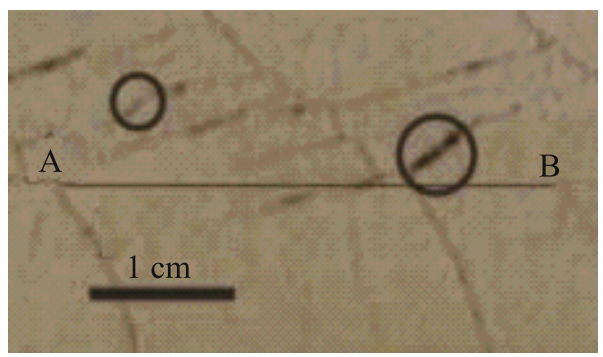

Figure 9 . High angle $\mathrm{R}$ shears joined by tension fractures (marked by black circles).

$\gamma=1.5)$ small Y shears were initiated from the tips of low angle $\mathrm{R}$ shears and were extended to join with the adjacent $\mathrm{Y}$ shears - thus giving rise to a through-going fault.

\section{1b Models with $18<T^{\prime}<25$}

First (at a minimum $\gamma=0.7$ ) a set of numerous incipient $\mathrm{R}^{\prime}$ shears (at an angle of $85^{\circ}-88^{\circ}$ ) were developed which was immediately followed by a set of $\mathrm{R}$ shear $\left(23^{\circ}-28^{\circ}\right)$. With progressive deformation $\mathrm{R}^{\prime}$ shears rotate and gradually become offset as passive markers due to slip along the $\mathrm{R}$ shears (figure 8). Finally (at a minimum $\gamma=1$ ), the $\mathrm{R}$ shears were joined with each other by a set of newly formed tension fractures (figure 9).

\section{1c Deformation of models of $T^{\prime}>25$}

First (at a minimum $\gamma=0.8$ ) $\mathrm{R}^{\prime}$ shears were formed followed by the formation of $\mathrm{R}$ shears 
$\left(18^{\circ}-22^{\circ}\right)$. With increasing deformation, displacement took place along both the sets of fractures and gradually two $\mathrm{R}^{\prime}$ shears were joined by an $\mathrm{R}$ shear (at a minimum $\gamma=1$ ) (figure 10). The fractures also opened up by wall-perpendicular displacement. Finally (approx. $\gamma=1.2$ ) such a set of three fractures $\left(\mathrm{R}^{\prime}-\mathrm{R}-\mathrm{R}^{\prime}\right)$ formed a $\mathrm{Z}$-shaped sigmoidal vein (figure 11).

\subsection{Simple shear with shear-normal compression (heterogeneous transpression)}

$\mathrm{R}$ shears initiate at lower angle in the thinner models (at minimum $\gamma=0.3$ and shortening 0.055) and higher angle in the thicker models. For example as shown in figure 12(a), in case of deformation with $15^{\circ}$ angle of convergence, for layers with $T^{\prime}=5$ maximum $\mathrm{R}$ shears were initiated between $0^{\circ}$ and $20^{\circ}$, very few between $20^{\circ}$ and $30^{\circ}$ but not a single $\mathrm{R}$ shear was initiated at an angle greater than $30^{\circ}$. For layers with $T^{\prime}=10,20$ and 30 there was no fracture at an angle less than $10^{\circ}$. For layers with $T^{\prime}=30^{\circ}$, no fracture was initiated even at an angle less than $20^{\circ}$ and maximum number of fractures were initiated at angles between $30^{\circ}$ and $40^{\circ}$. For $30^{\circ}$ angle of convergence as shown in figure $12(\mathrm{~b})$, in layers with $T^{\prime}=5$ maximum $\mathrm{R}$ shears were initiated between $20^{\circ}$ to $30^{\circ}$ and few between $10^{\circ}$ and $20^{\circ}$. But for layers with $T^{\prime}=30$ most of the $\mathrm{R}$ shears were initiated between $30^{\circ}$ and $40^{\circ}$ and a very few between $20^{\circ}$ and $30^{\circ}$.

With increasing deformation in models with $2<T^{\prime}<15$, the low angle $\mathrm{R}$ shears were joined by $\mathrm{Y}$ shears. Finally (at a minimum $\gamma=0.4$ and shortening of 0.067) the $\mathrm{R}$ and $\mathrm{Y}$ shears merged with one another to form an anastomosing network isolating lenses of undeformed material (figure 13). In the models with $15<T^{\prime}<25$, first (at a minimum $\gamma=0.4$ and shortening of 0.025$)$ the high angle $R$ shears $\left(25-30^{\circ}\right)$ were formed and at a later stage (at a minimum $\gamma=0.5$ and shortening of 0.028 ) those were cut across by low angle $\mathrm{R}$ shears $\left(10-13^{\circ}\right)$ (figure 14). In the even thicker layers $\left(T^{\prime}>25\right)$ $\mathrm{R}$-within-R shears were formed (figure 15). At an early stage (at a minimum $\gamma=0.6$ and shortening of 0.062 ) small $\mathrm{R}$ shears were formed at an angle of $30-35^{\circ}$ to the master fault. Those right stepping $\mathrm{R}$ shears were arranged in an en echelon pattern along a linear zone which was at an angle of $\sim 23^{\circ}$ with the master fault. With progressive deformation (at a minimum $\gamma=0.7$ and shortening of 0.1 ) those small $\mathrm{R}$ shears rotated a little bit clockwise, propagated lengthwise and joined with one another (possibly by $\mathrm{P}$ shears) to give rise to a throughgoing $\mathrm{R}$ shear at an angle around $20^{\circ}$ with the master fault. Gradually the major displacement took place along those large $\mathrm{R}$ shears which remained markedly angular with the basement fault.



Figure 10. Early $\mathrm{R}^{\prime}$ shears followed by low angle $\mathrm{R}$ shears.

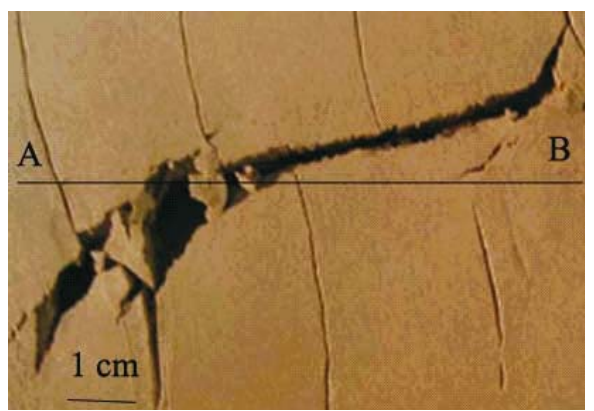

Figure 11. Z-shaped sigmoidal vein formed by joining of $\mathrm{R}$ and $\mathrm{R}^{\prime}$ shear.

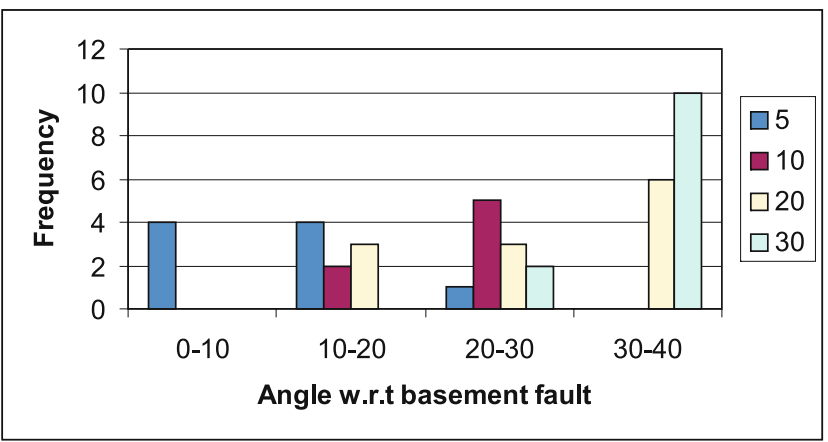

(a)

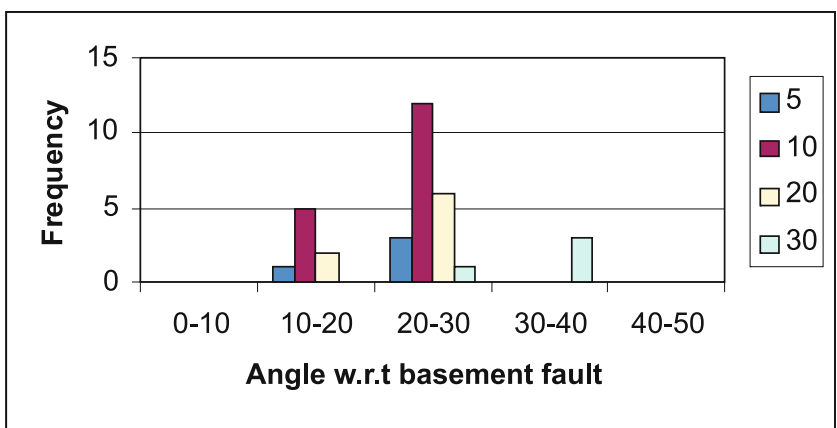

(b)

Figure 12. Frequency distribution plot of variation in initial angle of $\mathrm{R}$ shear w.r.t the basement fault. (a) Heterogeneous transpression with a compression at an angle of $15^{\circ}$. (b) Heterogeneous transpression with a compression at an angle of $30^{\circ}$. 


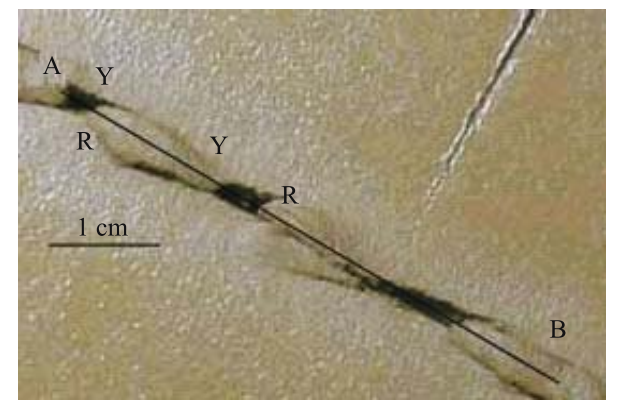

Figure 13. $\mathrm{R}$ and $\mathrm{Y}$ shears merged with one another to form an anastomosing network, isolating lenses of undeformed material. RR - Rshear; YY - Yshear.

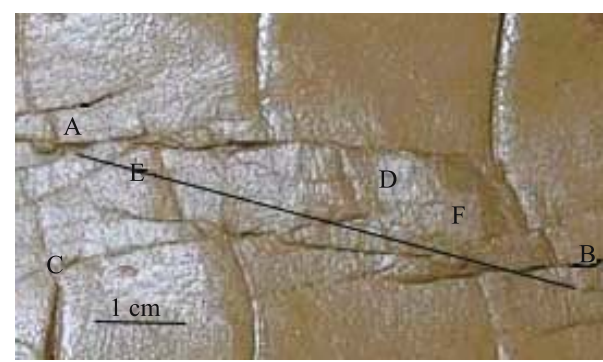

Figure 14. High angle R shears (CD) later cut across by low angle $\mathrm{R}$ shears (EF).

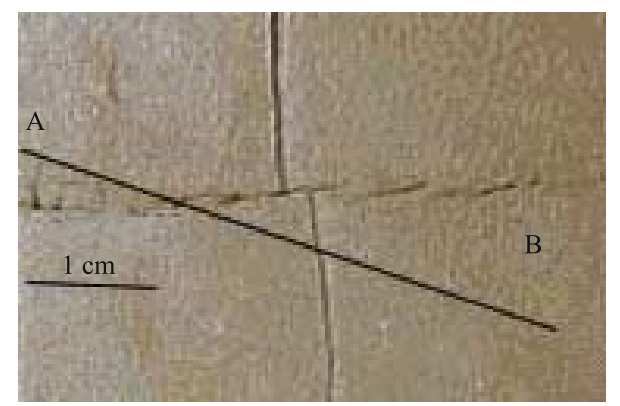

Figure 15. Formation of Riedel-within-Riedel shears.

\section{Discussion}

The present series of experiments clearly show that the initiation and linkage of surface fractures are largely controlled by the depth of the underlying strike-slip fault and by the boundary condition of deformation. In general, $\mathrm{R}$ and $\mathrm{R}^{\prime}$ shears developed at a higher angle with the shear plane with increasing component of pure shear added to bulk simple shear. For comparable thickness of the clay models (e.g., $T^{\prime} \sim 8$ ), maximum $\mathrm{R}$ shears formed at $15-20^{\circ}$ with the shear plane in pure wrenching, at $20-25^{\circ}$ for $\alpha=15^{\circ}$ and at $25-30^{\circ}$ for $\alpha=30^{\circ}$. This is because the instantaneous stretching axes (ISA) is oriented at a higher angle with respect to the shear plane in transpression than in simple shear (figure 1), and increase with increasing pure shear component. Also, $\mathrm{R}$ shears initiate at a larger angle with the shear plane (master fault) with increasing thickness of the overburden (figures 5 and 12). It is expected that the individual R-shears have a helicoidal geometry in three dimensions (e.g., Naylor et al 1986) and strike at a higher angle with the underlying fault as one goes above and farther from the sharp fault plane below. The angle (with respect to the shear plane) of the new R-shear fractures on the surface of a thick model will therefore be generally higher than that on a thin overburden.

For the thinner models, where the effect of the basement fault was pronounced, the major fractures on the surface were $\mathrm{R}$ shears which were followed by Y shears. Finally R and Y shears were joined up to give a through-going fracture parallel to the basement fault. The surface fracture pattern map of Canibal Quadrangle over Chixoy Polochic Fault, Guatemala (figure 3 of Erdlac and Anderson 1982) shows a similar R and Y shear network without any significant $\mathrm{R}^{\prime}$ and/or $\mathrm{P}$ shear. Notably, P-shears were never prominent in the present series of experiments. Naylor et al (1986) observed that new fractures were not kinematically 'required' if already formed fractures (e.g., $\mathrm{R}$-shears in their transtensional set-up) can take up large displacements induced by the master fault. Our observation confirms that in thin overburden, the shearing effect of basement fault will be very strong and Y shears will appear early, and join the R shears. Once formed, this Y-shear dominated system will be sufficient to take up all the displacement and no other shear fracture will appear.

With increasing thickness, the influence of the basement fault on the surface of the clay block was reduced and the developing shear zone becomes wider. This widening of the shear zone away from the master fault has been observed by most of the earlier workers (Bartlett et al 1981; Naylor et al 1986). Under heterogeneous simple shear, in the layers of intermediate thickness, incipient $\mathrm{R}^{\prime}$ shears develop which were immediately followed by $\mathrm{R}$ shear. The $\mathrm{R}^{\prime}$ shears soon became inactive and rotated passively to a sigmoidal shape (figure 8). Tchalenko (1970) has also described that $\mathrm{R}^{\prime}$ fractures form early and due to their large angle with the shear direction they soon became passive and distorted in an S-shape. For very thick models $\left(T^{\prime}>25\right) \mathrm{R}^{\prime}$ form first followed by $\mathrm{R}$ shears in the present experiments. In the sand model experiments of Naylor et al (1986), $\mathrm{R}^{\prime}$ shear developed only occasionally when there was a substantial overlap between adjacent $\mathrm{R}$ shears. However, the present experiments show that the occurrence of $\mathrm{R}^{\prime}$ shears was controlled by the thickness of overburden rather than overlap of $\mathrm{R}$ fractures. Atmaoui et al (2006) has also shown in their experiments with clay models that the appearance of 


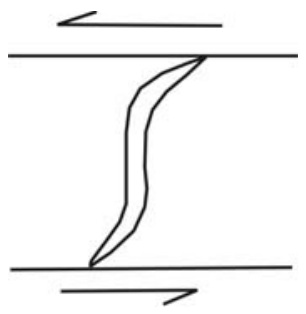

(a)

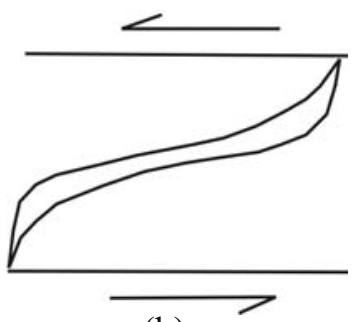

(b)

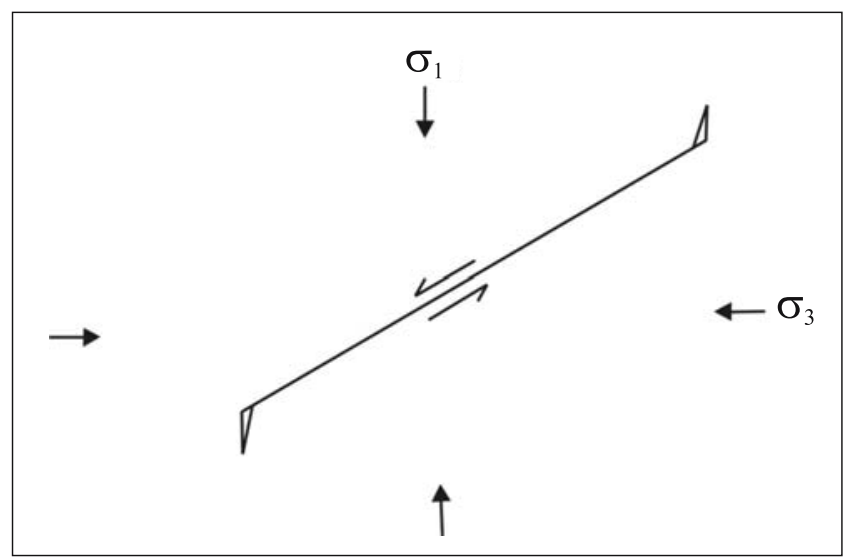

(c)

Figure 16. Schematic diagram representing sigmoidal veins formed under sinistral shear, (a) Opening up of tension fracture to form S-shaped vein; (b) joining of $\mathrm{R}$ and $\mathrm{R}^{\prime}$ shear to make Z-shaped vein; and (c) development of wing crack from a shear (Mode II) fracture under sinistral shear components (after Nemat-Nasser and Horii 1982). Note that here the principal compressive stress (parallel to ISA) are vertical, whereas in bulk sinistral simple shear, they will be at $45^{\circ}$ to the shear zone boundary.

$\mathrm{R}^{\prime}$ shear was controlled by the thickness of the overburden. In the experiments of Coelho et al (2006) the development of $\mathrm{R}^{\prime}$ shears was independent of $\mathrm{R}$ shears and $\mathrm{R}^{\prime}$ shears clearly dominated over R shears. Tchalenko (1970) suggested that $\mathrm{R}^{\prime}$ shears develop in more brittle (i.e., less water saturated) clay, but our experiments show that $\mathrm{R}^{\prime}$ develop after a critical thickness $\left(T^{\prime} \sim 18\right)$ of the model, water content remaining constant. Similar $\mathrm{R}$ and $\mathrm{R}^{\prime}$ dominated zones, as formed in our experiments, are observed in the fracture pattern map of Cuilco Quadrangle over Chixoy Polochic Fault, Guatemala, (figure 5(c) of Erdlac and Anderson 1982) and also in the eastern part of the damage zone of Dasht-e-Byaz earthquake, Iran (figure 8 of Tchalenko and Ambraseys 1970). The differing geometry of the secondary fracture zone over subsurface faults may therefore reflect not only the stage of their evolution (cf. Ahlgren 2001), but also the depth of the master fault.

It is interesting to find that most of the $\mathrm{R}$ shears initially behave as true shear fractures with normal (synthetic to basement fault) slip sense, but in thicker models, they tend to open up considerably with increasing finite strain, and thus they essentially behave as hybrid (Mode I-Mode II) fractures. This may be due to the higher angle of formation of these R shears and their tendency to partly rotate during continued shearing. Eventually they became sub-parallel to the ISA $\mathrm{Imin}_{\text {and }}$ started to open up. In cases where $\mathrm{R}^{\prime}$ shears are already well developed, the tips of these $\mathrm{R}$ shears join them to form $\mathrm{Z}$ shaped veins (discussed below) rather than forming new $\mathrm{P}$ shears and join up with adjoining $\mathrm{R}$ shears. This feature is only observed in thick $\left(T^{\prime}>25\right)$ overburden because appreciable rotation of $\mathrm{R}^{\prime}$ shears needs the late appearance of $\mathrm{Y}$ (and consequently the through-going fault), which is achieved only in thick models.

The sigmoidal veins which develop from extension fractures (tension gashes) always show an S-shaped asymmetry under sinistral shear. The tips of such veins made an angle of $45^{\circ}$ with the shear direction and the central part makes a higher angle (Ramsay and Huber 1983; p. 24). But in the present experiments the veins which were formed by joining of $\mathrm{R}^{\prime}-\mathrm{R}-\mathrm{R}^{\prime}$ show a Z-shaped asymmetry under sinistral shear. Here the tips made a higher angle with the shear direction as they were constituted of $\mathrm{R}^{\prime}$ shears and the central part made a lower angle as it was formed by $\mathrm{R}$ shear (figure 16a, b). In our opinion, the extension of $\mathrm{R}$-shears into adjacent $\mathrm{R}^{\prime}$ shears at either end, to make a Z-shaped fracture can be possibly explained by the 'wing crack' model (Nemat-Nasser and Horii 1982). Sinistral slip on an R-shear fracture leads to the development of 'wing cracks' at its tips as demonstrated in figure 16(c). Ideally, the wing cracks should have an orientation parallel to the principal compressive stress (i.e., parallel to ISA max $_{\max }$ in a homogeneous clay model like ours). Instead, the $\mathrm{R}$ shear segments of the Z-shaped fractures extend into the $\mathrm{R}^{\prime}$ shears at both ends in our experiment, which deviated from the ideal $45^{\circ}$ orientation of the ISA. However, close examination of figure 10 reveals that the cracks at the end of $R$ shears were possibly initiated parallel to ISA as seen at one end of the $\mathrm{R}$ shear fracture (white arrow). Whenever there is an $\mathrm{R}^{\prime}$ shear fracture present in the vicinity, these initial wing cracks would take the already existing fracture to propagate, as is observed at the other end of the $R$ shear in figure 10, and would thus form a final 
$\mathrm{R}^{\prime}-\mathrm{R}-\mathrm{R}^{\prime}$ fracture geometry seen in figure 11 . Body rotation of the $\mathrm{R}$ shears also contributed to the opening up of the fractures in this case. Coelho et al (2006) described pennant veins which were formed by linkage of $\mathrm{R}$ and $\mathrm{R}^{\prime}$ shears and show an $\mathrm{S}$ - or Z-shaped asymmetry under sinistral sense of shear from Purros Mylonite Zone, Namibia. However, they suggested that the veins are in majority $\mathrm{S}$-shaped, formed by two $\mathrm{R}$ and one $\mathrm{R}^{\prime}$ shear ( $\left.R-R^{\prime}-R\right)$, as the $R^{\prime}$ shears were less abundant than R. Our experiments, on the other hand, show that $\mathrm{R}^{\prime}$ shear set may be well developed in thicker overburden blocks and may lead to frequent Z-shaped $\mathrm{R}^{\prime}-\mathrm{R}-\mathrm{R}^{\prime}$ veins. Moreover, their pennant veins have typical 'double flag' geometry and can be easily recognized from sigmoidal tension gashes, as the central part does not open up (or close down eventually). But veins produced in our experiments have a prominent wall normal displacement and look quite similar to typical sigmoidal veins (figure 11), but with an opposite asymmetry (figure 16a, b). This 'atypical' antithetic structure may cause a gross misinterpretation of movement sense on buried master faults, if they are not recognized and separated from 'typical' sigmoidal tension gashes.

Under heterogeneous transpression, a set of low angle $\mathrm{R}$ shears is seen to cross-cut a set of early formed high angle $\mathrm{R}$ shears in models of intermediate thickness $\left(15<T^{\prime}<25\right)$. We think that the higher angle $\mathrm{R}$ shears formed in response to the transpressional strain, as theoretically expected (figure 1b). As deformation progressed, the central portion of the model, directly overlying the master fault, became weaker and more influenced by the basement fault. Deformation in this zone became more wrench-dominated and a new set of low angle $\mathrm{R}$ shear fractures formed in this zone, overprinting the earlier higher angle $\mathrm{R}$ shears. In the thicker models, only $\mathrm{R}$ shears or 'Riedelwithin-Riedel' shears are formed. Major displacement takes place along the large $\mathrm{R}$ shears which remained at an angle of around $20^{\circ}$ with the basement and no fault-parallel Y shears formed. This is in sharp contrast with the experiments of Naylor et al (1986) where the isolated high angle $\mathrm{R}$ shears ultimately joined up by lower angle Riedel shears to form a wide, master fault-parallel damage zone. However, the experiments with stratified sand models under distributed transpression (Schreurs and Colletta 1998), show that at an early stage separate zones of en-echelon synthetic $\mathrm{R}$ shears (at an angle between 24 and $37^{\circ}$, depending upon the strain rate ratio) were formed. At final stage the major deformation is accommodated on oblique slip fault zones with an overall surface strike at an angle to the bulk shear direction $\left(15-20^{\circ}\right.$ in low strain ratio), similar to what we observed. In our opinion, this contrasting geometry of Riedel shear zone is due to the fact that Naylor et al (1986) first compressed the package and then sheared, whereas both Schreures and Colletta (1998) and the present experiments used simultaneous shearing and compression.

\section{Acknowledgements}

This study was financially supported by grants from Department of Science and Technology, India (DST Project No. SR/WOS-A/ES-15/2004). The experimental apparatus was fabricated in the University Science Instrumentation Centre, Delhi University. The critical reviews by two anonymous referees and editorial help and suggestion from Dr A Manglik have helped to improve the paper.

\section{References}

Ahlgren S G 2001 The nucleation and evolution of Riedel shear zones as deformation bands in porous sandstone; J. Struct. Geol. 23 1203-1214.

Atmaoui N, Nina K, Bernhard S and Diethard K 2006 Initiation and development of pull-apart basins with Riedel shear mechanism: insights from scaled clay experiments; Int. J. Earth Sci. 95 225-238.

Bartlett W L, Friedman M and Logan J M 1981 Experimental folding and faulting of rocks under confined pressure. Part IX. Wrench faults in limestone layers; Tectonophys. 79 255-277.

Coelho S, Passchier C and Marques F 2006 Riedel-shear control on the development of pennant veins: Field example and analogue modeling; J. Struct. Geol. 28 1658-1669.

Davis G H, Bump A P, Garcia P E and Ahlgren S G 1999 Conjugate Riedel deformation band shear zones; J. Struct. Geol. 22 169-190.

Erdlac R J and Anderson T H Jr 1982 The Chixoy-Polochic fault and its associated fractures in western Guatemala; Geol. Soc. Amer. Bull. 93 57-67.

Gammond J F 1983 Displacement features associated with fault zones: a comparison between observed examples and experimental models; J. Struct. Geol. 5 33-45.

Katz Y, Weinberger R and Aydin A 2004 Geometry and kinematic evolution of Riedel shear structures, Capitol Reef National Park, Utah; J. Struct. Geol. 26 491-501.

Kim Y S, Peacock D C P and Sanderson D J 2003 Mesoscale strike-slip faults and damage zones at Marsalforn, Gozo Island, Malta; J. Struct. Geol. 25 793-812.

Marques F O 2001 Flow and fracturing of clay: analogue experiments in pure shear; Tectonic Modeling: A volume in Honor of Hans Ramberg; Geol. Soc. Amer. Bull. Memoir 193 261-270.

Naylor M A, Mandl G and Sijpesteijn C H K 1986 Fault geometries in basement-induced wrench faulting under different initial stress states; J. Struct. Geol. 8 $737-752$.

Nemat-Nasser S and Horii H 1982 Compression-induced non-planar crack extension with application to splitting, exfoliation and rockburst; J. Geophys. Res. 87 6805-6821. 
Pollard D D, Segall P and Delaney P T 1982 Formation and interpretation of dilatant echelon cracks; Geol. Soc. Amer. Bull. 93 1291-1303.

Ramsay J G and Huber M I 1983 The Techniques of Modern Structural Geology; Vol. 1, Strain Analysis (London: Academic Press).

Riedel W 1929 Zur Mechanik geologischer Brucherscheinungen. Zentral-blatt fur Mineralogie Abteilung B, 354-368.

Sanderson D and Marchini R D 1984 Transpression; J. Struct. Geol. 6 449-458.

Schreurs G 1994 Experiments on strike-slip faulting and block rotation; Geology 22 567-570.

Schreurs G and Colleta B 1998 Analogue modeling of faulting in zones of continental transpression and transtension; In: Continental Transpressional and Transtensional Tectonics, Holdsworth R E, Strachan R A and Dewey J F (eds) Geol. Soc. London Spec. Publ. 135 59-79.

Segall P and Pollard D D 1980 Mechanics of discontinuous faults; J. Geophys. Res. 85 4337-4350.
Smith J V and Durney D W 1992 Experimental formation of brittle structural assemblages in oblique divergence; Tectonophys. 216 235-253.

Swanson M T 1988 Pseudotachylyte-bearing strike-slip duplex structures in the Fort Foster Brittle Zone, S. Maine; J. Struct. Geol. 10 813-828.

Tchalenko J S 1970 Similarities between shear zones of different magnitudes; Geol. Soc. Amer. Bull. $\mathbf{8 1}$ 1625-1640.

Tchalenko J S and Ambraseys N N 1970 Structural analysis of the Dasht-e Byaz (Iran) earthquake fractures; Geol. Soc. Amer. Bull. 81 41-66.

Tikoff B and Peterson K 1988 Physical experiments on transpressional folding; J. Struct. Geol. 20 661-672.

Wilcox R E, Harding T P and Seely D R 1973 Basic wrench tectonics; The Am. Assoc. Petrol. Geol. Bull. $\mathbf{5 7}$ 74-96.

Withjack M O and Jamison W R 1986 Deformation produced by oblique rifting; Tectonophys. 126 99-124. 